\title{
Supersolubility of Hydrogen in Acidic Solution in the Vicinity of Hydrogen-Evolving Platinum Cathodes in Different Surface States
}

\author{
Shigeo SHIBATA*
}

\begin{abstract}
The supersolubility of hydrogen in $0.5 \mathrm{M} \mathrm{H}_{2} \mathrm{SO}_{4}$ in the vicinity of a $\mathrm{H}_{2}$-evolving $\mathrm{Pt}$ cathode was estimated from the concentration overpotential, $\eta_{\mathrm{H}_{2}}$, which was measured by extrapolating the potential decay curve after interruption of the current to time zero. The measurement was performed for three electrodes having different surface stats: a smooth, a platinized and a mechanically ground surface. The electrolysis current was in the range of $0.2-800 \mathrm{~mA} / \mathrm{cm}^{2}$. Below about $3 \mathrm{~mA} / \mathrm{cm}^{2}, \eta_{\mathrm{H} 2}$ increased linearly with $\log i$, independent of the surface state. The $\eta_{\mathrm{H}_{2}}-\log i$ curve for the ground electrode was flattened at $i>5 \mathrm{~mA} / \mathrm{cm}^{2}$ and then reached a limiting value of $41 \mathrm{mV}$ at about $100 \mathrm{~mA} / \mathrm{cm}^{2}$. This limiting value corresponds to the supersolubility of 23 defined by a ratio $C^{*} / C^{\circ}$, where $C^{*}$ is the concentration of hydrogen in the vicinity of the electrode surface and $C^{\circ}$ the solubility of hydrogen under $1 \mathrm{~atm}$ at the same temperature. The $\eta_{\mathrm{H}_{2}}$ values for the smooth electrode attained to a limiting value of $66.5 \mathrm{mV}$ at $100 \mathrm{~mA} / \mathrm{cm}^{2}$ and for the platinized electrode $62.5 \mathrm{mV}$ at $500 \mathrm{~mA} / \mathrm{cm}^{2}$. These limiting values correspond to supersolubilities, 165 and 120 , respectively. The supersolubility was affected by the irregular structure rather than the roughness of the surface.
\end{abstract}

\section{Introduction}

The electrolyte solution in the vicinity of a electrode surface at which gas is evolving is generally supersaturated with the gas. Its supersolubility can be estimated from the concentration overpotential. Overpotentials observed during the passage of the electrolysis current are due to the following effects; an ohmic drop between the electrode surface and a tip of Luggin capillary, a reaction overpotential caused by retarded chemical reaction, an activation overpotential for charge transfer at the electrode and the concentration overpotential by a slow diffusion of active species. The first effect disappears immediately after interruption of the current, and the second and third effects decay in a $\mu$ sec-msec range ${ }^{11}$. Only the concentration overpotential decreasing slowly can be observed for some time after the interruption of the current. Clamroth and Knorr ${ }^{2}$ attempted to measure the concentration overfotential free from the other overpotentials by extrapolating

* Department of Chemistry, College of General Education, Tohoku University (Kawauchi, Sendai) the potential decay curve after the current interruption to time zero. Their experiment, however, was limited in a low current range, because the concentration overpotential formed with a large current density disappeared so rapidly that it was difficult to follow its change by the manual technique employed by them. We measured previously the concentration overpotential in a high current range by means of the oscilloscopic technique ${ }^{3}$. The result showed a good agreement with that obtained by a different method, a current reversal transient technique ${ }^{32,4)}$.

For the estimation of the supersolubility of hydrogen on $\mathrm{Pt}$ cathode having a complicated rough surface, such as a platinized electrode, the overpotential methcd mentioned above is more suitable than the current reversal method, because the data obtained by the former method requires no correction for the roughness factor of the surface in contrast with that obtained by the latter one. This paper describes the work carried out by the concentration overpotential method.

\section{Experimental}


The measurements were performed in a threecompartment glass cell at a constant temperature of $25 \pm 0.1^{\circ} \mathrm{C}$. The electrode studied was in the middle compartment, while in the other two were two smooth $\mathrm{Pt}$ counter electrodes of $2 \mathrm{~cm}^{2}$ in area connected in parallel. A hydrogen reference electrode (a platinized $\mathrm{Pt}$ ) was dipped into the $\mathrm{H}_{2}$-saturated solution of the same composition as in the measuring compartment. All potential values referred to this electrode.

The electrolyte solution was $0.5 M \mathrm{H}_{2} \mathrm{SO}_{4}$ prepared with analytical grade sulfuric acid and water distilled four times with a quartz still. The solution was pre-electrolysed with removable $\mathrm{Pt}$ electrodes for at least $24 \mathrm{~h}$. After opening the circuit by removing the electrodes, the solution was saturated with purified $\mathrm{H}_{2}$ gas for 5-6 $\mathrm{h}$ to remove any peroxide formed during the pre-electrolysis procedure.

Test electrodes were three $\mathrm{Pt}$ electrodes with different surface state (plates of $0.5 \mathrm{~cm}^{2}$ in geometric area); a smooth electrode (roughness factor, $R=1.38)$, a platinized electrode $(R=$ $190)$ and a mechanically ground electrode $(R=$ 4.1). The first electrode was heated to yellow glow in a hydrogen flame before the measurement. The second electrode was prepared by electrodeposition onto a smooth $\mathrm{Pt}$ plate. The platinization was carried out in $3 \%$ platinum (IV) chloride solution containing $0.03 \%$ lead acetate with $20 \mathrm{~mA} / \mathrm{cm}^{2}$ for $2 \mathrm{~min}$ at room temperature. The third electrode was prepared by griding a smooth electrode with a emery paper of No. 3. The test electrodes except the platinized electrode were first activated by repeated trianglar potential sweeps between $0.03-1.5 \mathrm{~V}$ in another cell containing a $\mathrm{N}_{2}$-saturated solution. The electrode was vertically placed in the measuring cell. The roughness factor of the test electrodes was determined by the triangular potential sweep method from the charge due to hydrogen adsorption at the surface, assuming the hydrogen monolayer charge of $210 \mu \mathrm{C} / \mathrm{real}$ $\mathrm{cm}^{25}{ }^{57)}$.

An electronic current interruptor was used instead of the circuit used in the previous work ${ }^{4}$. The electrode was polarized with a given constant cathodic current until its potential reached a steady value and then the current was interrupted. The decay of the potential immediately after the current interruption was traced with a cathode-ray oscilloscope. The value of $\eta_{\mathrm{H}_{2}}$ was determined by extrapolating the initial linear part (the region from $3-5$ to 25 msec after the interruption) of the trace to time zero. All the current densities are expressed in terms of geometric area.

\section{Results}

\subsection{Smooth electrode}

Figure 1 shows the results for the smooth electrode. The $\eta_{\mathrm{H}_{2}}$ value increased linearly with $\log i$ and then reached a limiting value of $66.5 \mathrm{mV}$ at $100 \mathrm{~mA} / \mathrm{cm}^{2}$. This overpotential value corresponds to the supersolubility, $S=$ 165 , when the ideal behavior of hydrogen is assumed. When the solution was vigorously stirred by passing $\mathrm{H}_{2}$ gas through the solution at the rate of $1.5 \mathrm{l} / \mathrm{min}$, the concentration overpotential disappeared almost completely at $i<$ $1.0 \mathrm{~mA} / \mathrm{cm}^{2}$. Above $1.0 \mathrm{~mA} / \mathrm{cm}^{2}$, however, it increased linearly with $\log i$ in parallel with the curve obtained without stirring and attained to the same limiting potential at $700 \mathrm{~mA} / \mathrm{cm}^{2}$.

\subsection{Platinized and ground electrodes}

The results for the platinized and the ground electrode are shown in Figs. 2 and 3. At $i<$ $3 \mathrm{~mA} / \mathrm{cm}^{2}, \eta_{\mathrm{H}_{2}}$ is virtually independent of the surface state. In this current range, there formed a few large bubbles hardly removable from the surface. On the ground surface, in addition to those, many small bubbles began to evolve at

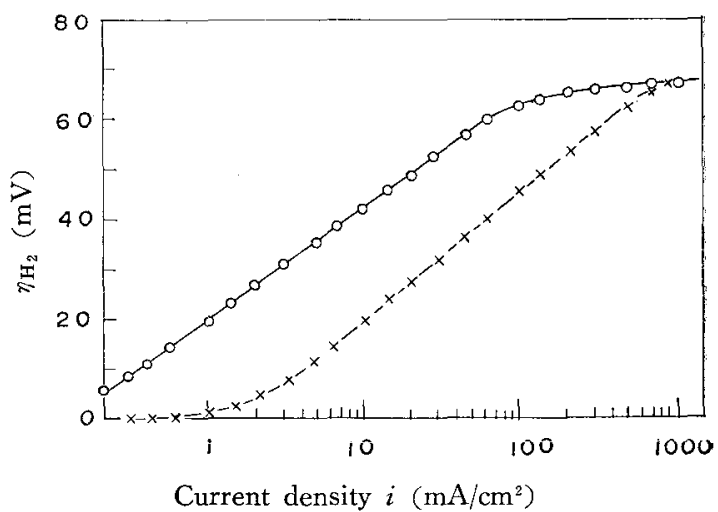

Fig. 1 Plots of $\eta_{\mathrm{H}_{2}} v s . \log i$ for smooth platinum electrode in $0.5 \mathrm{M} \mathrm{H}_{2} \mathrm{SO}_{4}$

$\mathrm{O}$ : Unstirring, $x$ : Stirring with $\mathrm{H}_{2}$ at the rate of $1.5 \mathrm{l} / \mathrm{min}$ 


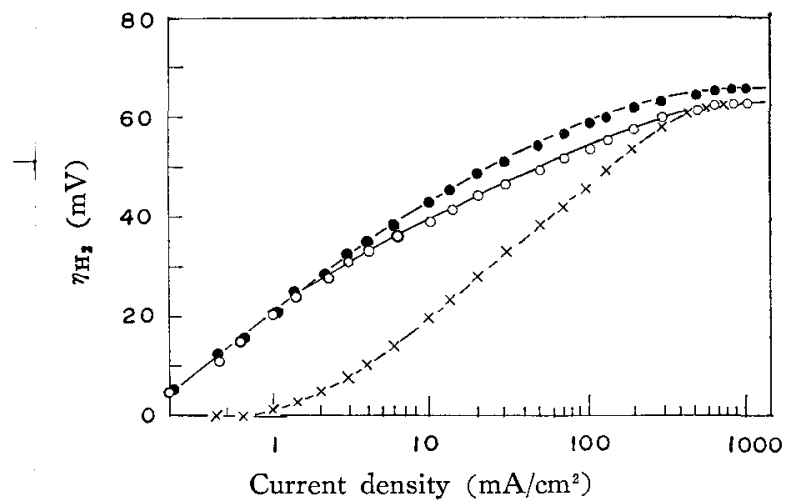

Fig. 2 Plots of $\eta_{\mathrm{H}_{2}}$ vs. $\log i$ for platinized platinum electrode in $0.5 \mathrm{M} \mathrm{H}_{2} \mathrm{SO}_{4}$

$\bigcirc$ : Unstirring, $x$ : Stirring with $\mathrm{H}_{2}$ at the rate of $1.5 l / \mathrm{min}, \quad$ : After heating

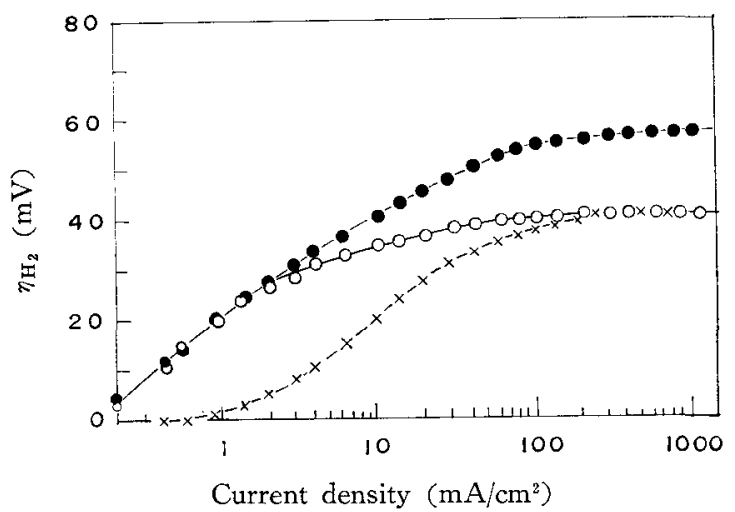

Fig. 3 Plots of $\eta_{\mathrm{H}_{2}}$ vs. $\log i$ for ground platinum electrode in $0.5 M \mathrm{H}_{2} \mathrm{SO}_{4}$

$\bigcirc$ : Unstirring, $\times$ : Stirring with $\mathrm{H}_{2}$ at the rate of $1.5 \mathrm{l} / \mathrm{min}$, : After heating

about $5 \mathrm{~mA} / \mathrm{cm}^{2}$. On the other two electrode surfaces, however, the fine bubbles did not appear until the current was increased up to $50-60 \mathrm{~mA} / \mathrm{cm}^{2}$. The $\eta_{\mathrm{H}_{2}}$ value at the platinized electrode increased almost linearly with $\log i$ and attained to a limiting value at about 500 $\mathrm{mA} / \mathrm{cm}^{2}$. In contrast with the curve for the platinized electrode, the one for the ground electrode was flattened at $i>5 \mathrm{~mA} / \mathrm{cm}^{2}$. The limiting $\eta_{\mathrm{H}_{2}}$ value for this electrode was much smaller than the values of the other two electrodes. The limiting values for the platinized and the ground surface were 62.5 and $41 \mathrm{mV}$, corresponding $S=120$ and 23 , respectively.

\section{Discussion}

The supersolubility of $\mathrm{H}_{2}$ in the vicinity of the $\mathrm{H}_{2}$-evolving cathode is considered to be dependent on the rates of formation and growth of bubbles ${ }^{8}$. It is well known that the formation of bubbles occurs at fixed spots acting as nucleation sites for their formation. The distribution and the activity of the nucleation sites on the ground surface are very different from those on the other two electrodes. The smallest $\eta_{\mathrm{H}_{2}}$ value is explained in terms of the irregular surface at which fine bubbles are very easily formed. By comparing the $\eta_{\mathrm{H}_{2}}-\log i$ curves for the three electrodes, it is indicated that the concentration overpotential is dependent on the irregularity rather than on the roughness of the surface. When the solution was vigorously stirred, the concentration overpotential was remarkably decreased (Figs. 1-3). This decrease in $\eta_{\mathrm{H}_{2}}$ is clearly due to the preferential removal of the supersaturated $\mathrm{H}_{2}$ by the vigorous stirring of the solution. The limitation of $\eta_{\mathrm{H}_{2}}$ at high current densities may be due to the sudden increase of the nuclei of bubbles ${ }^{i}$ and also to their removal by the following stirring effects; the stirring caused by the replacement of the surface electrolyte by evolving gas and the hydrodynamic convection caused by the bubbles leaving from the surface?

When the platinized electrode was heated to yellow glow in the flame, the roughness factor was reduced to 5.0 , and at the same time $\eta_{\mathrm{H}_{2}}$ rised up to the value close to that of the smooth electrode (Fig. 2). The roughness factor of the ground surface, when heated, was reduced to 1.9 , and the $\eta_{\mathrm{H}_{2}}$ increased to a value smaller than that of the smooth electrode. This may be caused by the irregular structure remained after heating.

\section{Acknowledgement :}

This work was financially supported by the Japan Chemical Research Foundation.

$<$ E458> (Received March 25, 1976)

\section{References :}

1) A.N. Frumkin, Acta Phisicochim. USSR, 18, 23 (1943).

2) R. Clamroth, C.A. Knorr, Z. Elektrochem. 57. 399 (1953). 
3) S. Shibata, Bull. Chem. Soc. Japan 33, 1635(1960).

4) S. Shibata, ibid. 36, 53 (1963).

5) S.B. Brummer, K. Cahill, J. Electroanal. Chem. 16, 205 (1968).

6) J.B. Lundquist, E. Washington, P. Stonehart, Electrochim. Acta 18, 343 (1973).
7) T. Biegler, D.A.J. Rand, R. Woods, J. Electroanal. Chem. 29, 269 (1971).

8) A.V. Hook, "Crystallization", p. 95 (1961), Rhinhold Publishing Co., New York.

9) L.J.J. Janssen, J.G. Hoogland, Electrochim. Acta 15, 1013; 18, 543 (1973). 